\title{
AN APPARATUS DESIGN FOR HIGH SPEED SEALING APPLICATIONS BASED ON SYSTEMATIC DESIGN APPROACH
}

\author{
E. Mutlu ${ }^{1}$, Z. Parlar ${ }^{1}$, V. Temiz ${ }^{1}$ \\ ${ }^{1}$ Department of Mechanical Engineering, Istanbul Technical University \\ (erenmutlu@itu.edu.tr)
}

\begin{abstract}
Contact seals used in high speed applications fail due to relatively friction and wear. Therefore, non-contact seals are used for high speed applications such as turbomacinery to increase system's efficiency. For this purpose, an apparatus design to determine performance of a new non-contact sealing geometry. In this study, the steps of systematic design approach that presented by G.Pahl and W.Beitz are applied to improve an apparatus for high speed sealing applications.
\end{abstract}

Keywords: Systematic approach, Apparatus design, Non-Contact sealing

\section{INTRODUCTION}

Systematic design provides an effective way to rationalize the design and production process. In original design, an ordered and stepwise approach will provide solutions that can be used again.

The problems and tasks in systematic approach are discussed with structuring method that makes it easier to recognize application possibilities for established solutions from previous projects and to use design catalogues. The stepwise concretization of established solution principles makes it possible to select and optimize them at an early stage with a smaller amount of effort.

With the rise of mechanization in the nineteenth century, as Redtenbacher ${ }^{[14]}$ pointed out early on his Principles of Mechanics and Machine Construction (Prinzipien der Mechanik und des Maschinenbaus), attention became increasingly focused on a number of characteristics and principles that continue to be great importance, namely; sufficient strength, sufficient stiffness, low wear, low friction, minimum use of materials, easy handling, easy assembly and maximum rationalization.

Modern systematic ideas were pioneered by Erkens ${ }^{[3]}$ in the 1920 s. He insisted on a step-by-step approach based on constant testing and evaluation, and also on the balancing of conflicting demands, a process that must be continued until a network of ideas (the design) emerges. A more comprehensive account of the "technique of design" has been presented by Wögerbauer ${ }^{[17]}$, whose contribution we consider to be the origin of systematic design. The author divides the overall task into subsidiary tasks, and these into operational and implemen- 
tational tasks. As a result of the World War II, a period of staff shortages in the $1960 \mathrm{~s}^{[16]}$ created a strong impetus to adopt systematic thinking more widely. Important pioneers were Kesselring $^{[6]}$, Tschochner ${ }^{[15]}$, Niemann ${ }^{[12]}$, Mataousek ${ }^{[10]}$ and Leyer ${ }^{[9]}$, their work continues to provide most useful suggestions for handling the individual phases of systematic design.

In 1970s, Gerhard Pahl and Wolfgang Beitz pointed out the fundamentals of modern systematic design on their Engineering Design - A Systematic Approach (Konstruktionslehre Grundlagen Erfolgreicher Produktentwicklung - Methoden und Anwendung) ${ }^{[13]}$ Based on their thoughts, the problem and task are dealt with as an abstract in the best possible and function structures are formed with the help of established solution methods. After determining the expectations from the design, certain technical and economical evaluation criteria are used to develop the most appropriate solution method for the given problem.

In this study, the systematic design phases that presented by G. Pahl and W. Beitz are applied to design process of the apparatus that planned to be developed to determine the characteristics of non-contact seals and tried to obtain the most appropriate solution.

\section{NON-CONTACT SEALS}

\subsection{Non-contact dynamic seals}

Seals used at high speed applications lose its function due to remarkably high friction and wear resulting in a decrease in service life. Therefore, non-contact seals (dynamic seals) are used for high speed application such as turbomacinery to increase system's efficiency. The most prominent features of non-contact seals are:

- Very low friction

- High speed

- Absence of wear, especially if operating in gas at high speed

- No excessive heating is observed on the sealing area

- Long service life

- Capability to deal with contamination with minimal wear

These seal types are referred as dynamical due to working only when the system is running. Although there are many applications of non-contact seals, the most commonly used dynamic seals are:

- Labyrinth seals

- Honeycomb and hole slot seals

- Brush seals

- Leaf seals (Lamella seals)

- Screw seals (Viscoseals) 


\subsection{Screw seals}

Screw seals (also known as contactless screw seals) are one of the very few clearance seals that have the capability to effectively seal a liquid. It is therefore able to provide a low friction and reliable sealing (Figure 1).

In this seal, the flank of a thread forms the slanted barrier and diverts the circumferential shear flow induced by the rotating shaft. The pressure of the sealed fluid causes flow towards the atmospheric side, but by selecting the appropriate sense of rotation of the thread, the flank directs the entrained fluid back towards the sealed space. In this case, a fluid film, generally called transition zone, occurs at a location close to the high pressure zone. This film should be within the boundaries of screw seal.

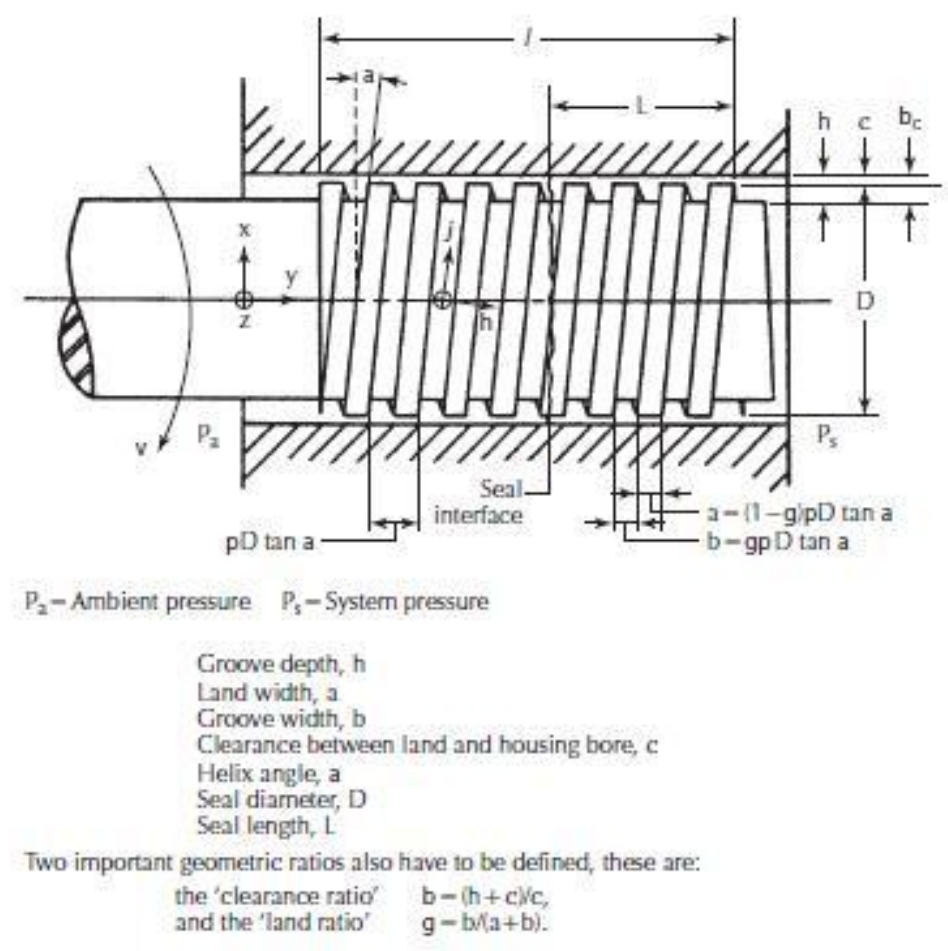

Figure 1. Screw seal. (see [4])

Some advantages of the screw seals are; no wear, absence of frictional heating, no power loss owing to low friction, no extra lubrication, long service life, ease of assembly and minimal mounting space. However, there are also two distinct disadvantages. The seal is only effective when the shaft is rotating and close clearances are required to provide sealing.

The seal can be manufactured either as a helical screw form in a cylindrical surface of as a spiral on a radial face (Figure 2). The sealing performance is virtually the same whether the thread is cut in the bore or on the shaft. The seal depends on the viscous flow generated between the rotating shaft and stationary housing. The relative movement of the plain surface past the thread form creates a viscous flow and hence generates pressure dependent on the clearance, thread dimensions, rotation speed and fluid viscosity. A non-contacting leak-free seal can be established if the screw seal can be arranged to match the return flow rate $Q_{R}$ to the leak flow rate $\mathrm{Q}_{\mathrm{L}}$ (Figure 2). 


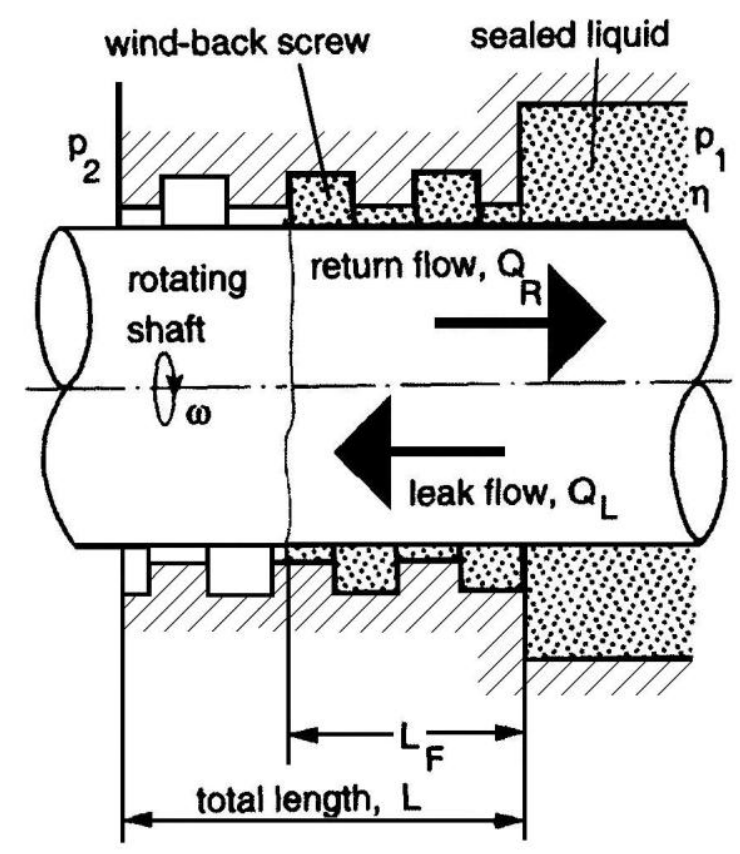

Figure 2. Flow rates on screw sealing. (see [11])

\section{DETERMINING SYSTEM REQUIREMENTS}

\subsection{The purpose of the study}

The main objective of this study is using the systematic design methods to design an apparatus that allows the experimental study on the performance characteristics of the screw seals.

\subsection{General structure of the apparatus}

In the current study, the apparatus will be designed by taking into consideration the principle of the screw seal. As mentioned before, dynamic seals are not effective when the shaft is not rotating. Therefore, a motor should be attached to the system to obtain rotational motion. Since the small radial clearance between the shaft and the seal is required to provide sealing, coaxial tolerances between shaft and hub must be very close. This situation should be regarded in the bearings selection and the most appropriate bearing type should be chosen. Furthermore, the principle of apparatus also should permit for testing of shafts with different screw geometries. The performance characteristic of the screw seal can be determined by obtaining the pressure distribution along the sealing surface. For this purpose, pressure sensors placed at certain intervals on the hub will have to be used. At the same time, sealing area should have a design that allows visualization of flow necessitating the hub material will be transparent. The resistance of the liquid friction inside the hub can be determined by obtaining the torque differences while the system is running, so that a torque-meter will have to be used. 


\subsection{Definition of the problem}

Discussing the general form of a problem in systematic design provides a wider approach towards the problem and allows obtaining the solution methods more easily. In this study, the problem is defined as follows "An Apparatus Design for High Speed Applications Based on Systematic Design Approach”.

\subsection{Preparation of the requirements list}

According to G. Pahl and W. Beitz, the requirements list that involves the design expectations should be prepared before determining the solutions methods.

Table 1. Requirements List

\begin{tabular}{|l|l|}
\hline & REQUESTS \\
\hline 1 & System can be operated at high speeds \\
\hline 2 & Provide a very low co-axiality tolerance \\
\hline 3 & System should allow testing shafts that have different screw geometries \\
\hline 4 & Transparent material should be used on hub \\
\hline 5 & The apparatus should be setup on a flat surface \\
\hline 6 & Pressure distribution along to sealing surface can be obtained \\
\hline 7 & The tank contain high pressure gas must be resist to 5 bar \\
\hline 8 & The tank should move in the shaft axis direction \\
\hline 9 & Gas pressure in the tank should be controlled with pressure gauge (A) \\
\hline 10 & Vibration of the system should be minimized \\
\hline 11 & The total cost of the system should be lower than 12 000 \$ \\
\hline 12 & Rotation speed can be adjustable in the system \\
\hline 13 & A torque-meter should be used for obtaining the resistance of liquid friction \\
\hline & (A) Alternate Requests \\
\hline
\end{tabular}

\section{SOLUTION METHODS}

Following the preparation of the requirements list, solution methods of the problem are determined. In this study, 3 different solution principles were presented for the basic function.

\subsection{First solution offer}

In the first solution method, the screw seal that contains the liquid in the transition area was used between the two pressure vessels (Figure 3). 


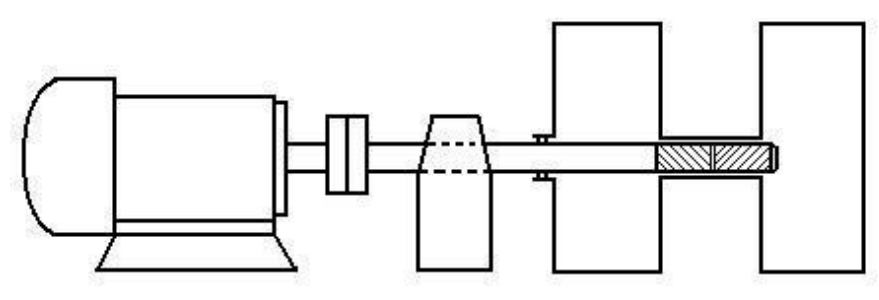

Figure 3. First solution offer.

There are two types of gas with different pressure in both pressure vessels. The liquid is pumped to the transition zone with the help of hydraulic circuit. The seal is provided with the proper screw geometry and the direction of shaft rotation. The functional structure of the first solution offer is shown in Figure 4.
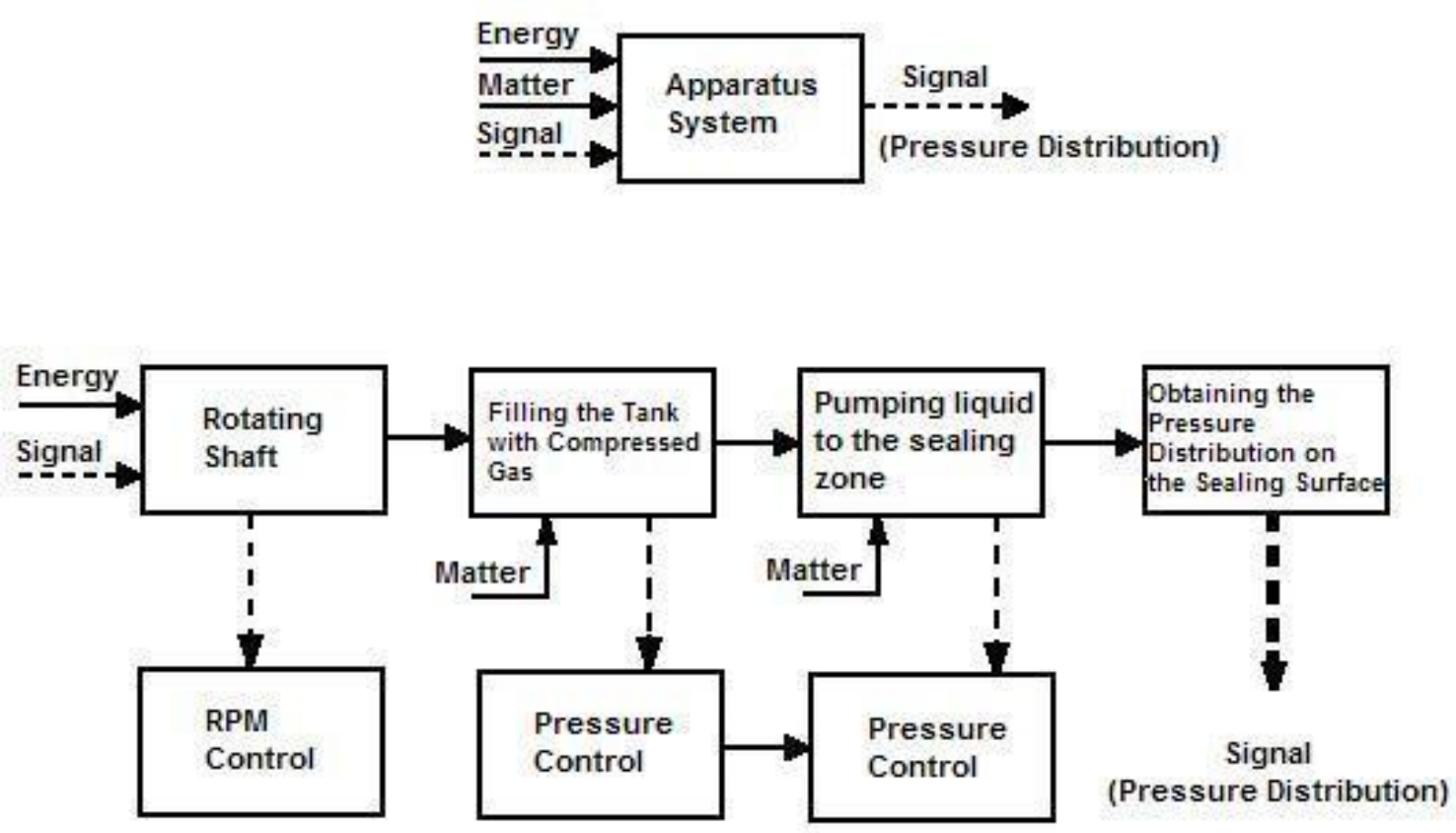

Figure 4. Functional structure of the first solution method.

\subsection{Second solution offer}

In the second solution method, the screw shaft is inserted into the transparent hub connected to the pressure vessel. This pressure vessel can move along the axis with the help of linear guide rail system (Figure 5). 


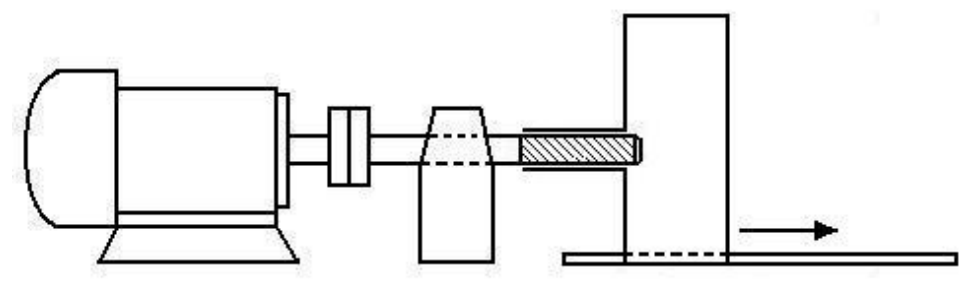

Figure 5. Second solution offer.

Axial movement of the pressure vessel enables to remove the screw shaft section. Thus, different screw geometries can be tested. The functional structure of the second solution offer is shown in Figure 6.
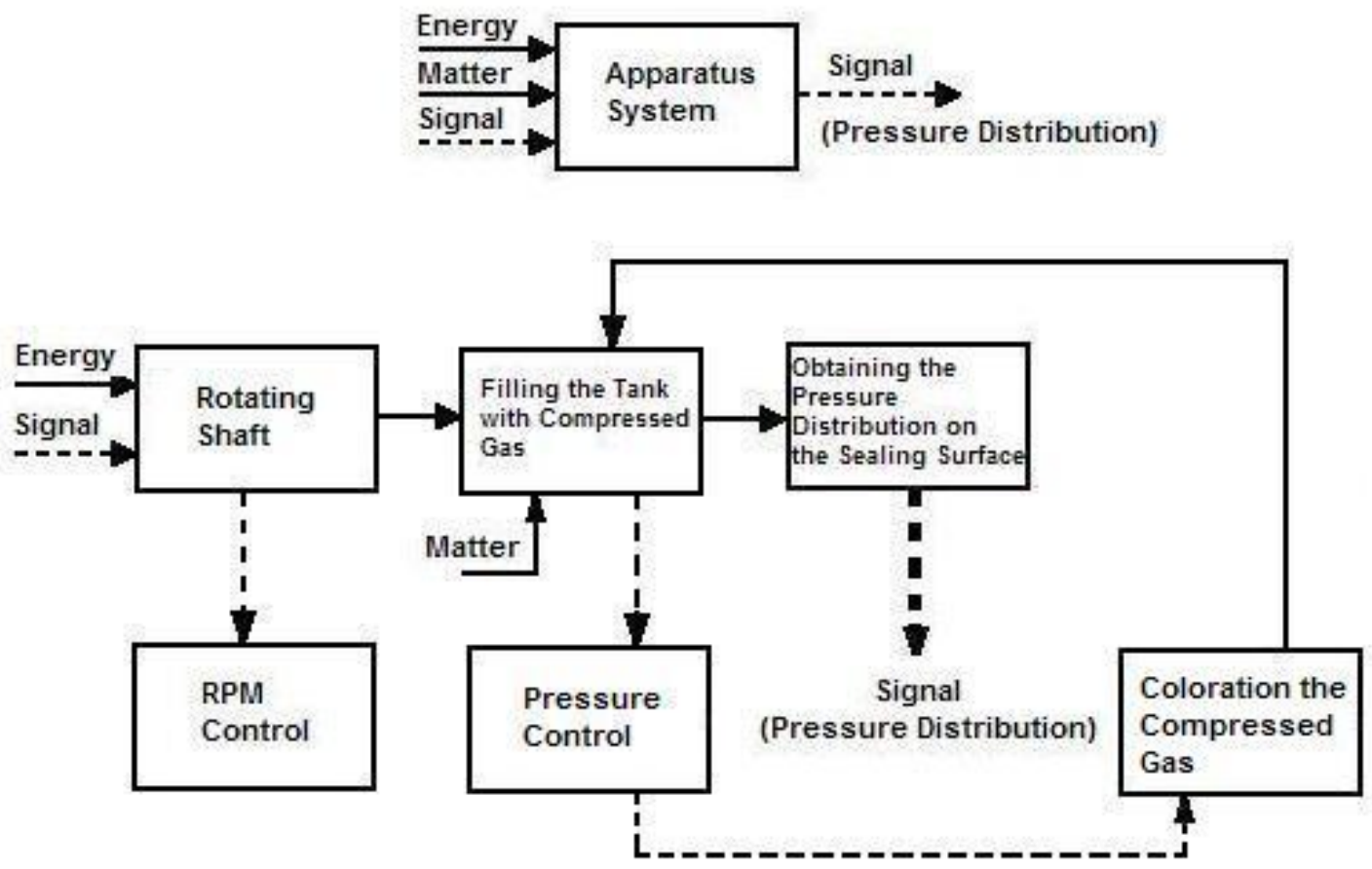

Figure 6. Functional structure of the second solution method.

\subsection{Third solution offer}

In the third solution method, differently from the second method, the seal was created as a helical screw form in a cylindrical surface (Figure 7). 


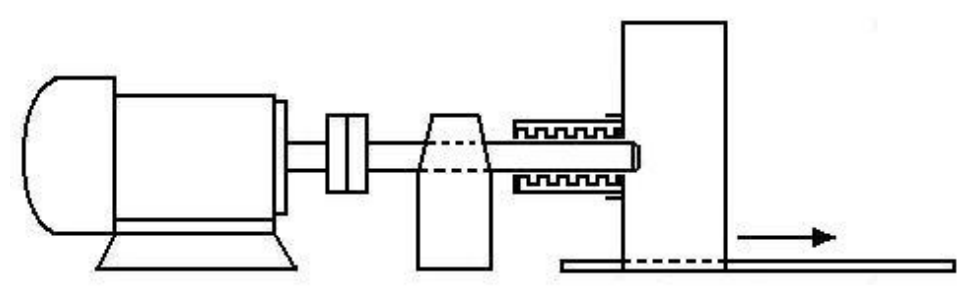

Figure 7. Third solution offer.

As with the second solution offer, pressure vessel can move along the axis too. The hub with screw is designed to be independent and removable from the pressure vessel, so that different screw geometries can be tested. The functional structure of the first solution offer is shown in Figure 8. These function structures (also known as verbal function structures) are generated with respect to the work of G. Pahl and W. Beitz.
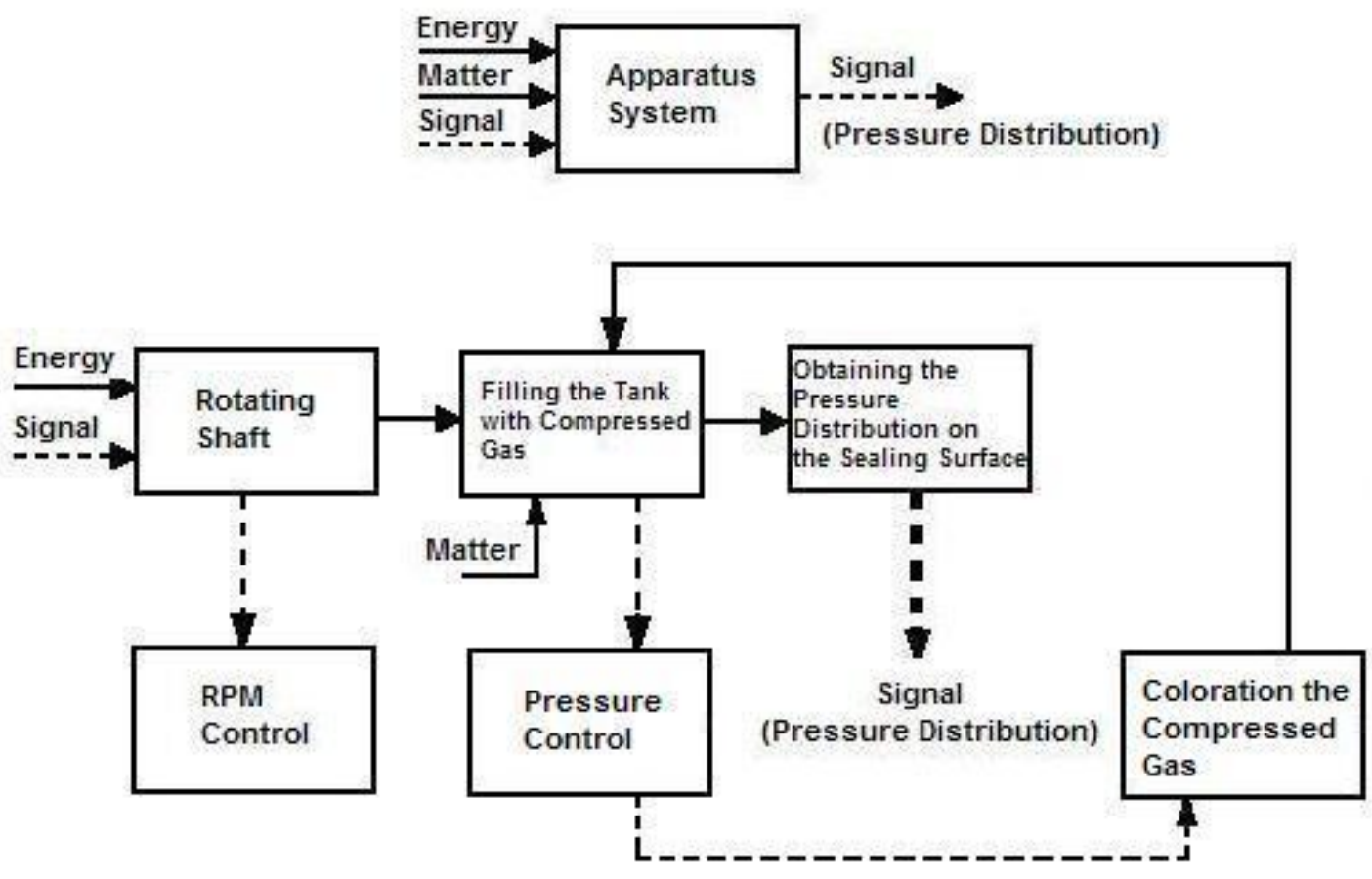

Figure 8 . Functional structure of the third solution method. 


\section{TECHNICAL AND ECONOMIC EVALUATION}

\subsection{Evaluating solution variants}

An evaluation is considered to determine the value, usefulness or strength of a solution with respect to a given objectives. An objective is indispensable since the value of a solution is not absolute, but must be set up in terms of certain requirements. An evaluation involves a comparison of concept variants or, in the case of a comparison with an imaginary ideal solution, a "rating" or degree of approximation to that ideal.

To establish evaluation criteria, we must first asses their relative contribution (weighting) to the overall value of the solution, so that relatively unimportant criteria can be eliminated before the evaluation begins. The evaluation criteria retained are given with "weighting factors" which must be taken into consideration during the subsequent evaluation step. A weighting factor is a real, positive number. It indicates the relative importance of a particular evaluation criterion (objective). Before proceeding to detailed design of the system, the weighting evaluation criteria system that shows the major and minor objectives was applied to compare alternative designs. Figure 9 illustrates the procedure, the box on the left shows the weighting factor of the relative target, and the box on the right shows the weighting factor of the total system. In weighting evaluation criteria system, weightings are based on factors ranging from 0 to 1 .

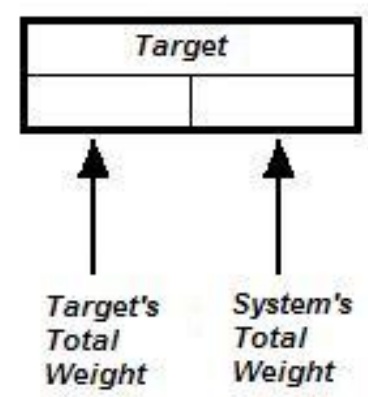

Figure 9. A sample of weighting evaluation criteria system.

Accordingly, the fundamental issues to be compared between the solution methods are listed as follows:

- Testability

- Function reliability

- Cost

- Ease of manufacturing

After the determination of all targets, a structure shown in Figure 10, where the weighting factors of targets, was created. The weighting factors were given according to the order of importance. 


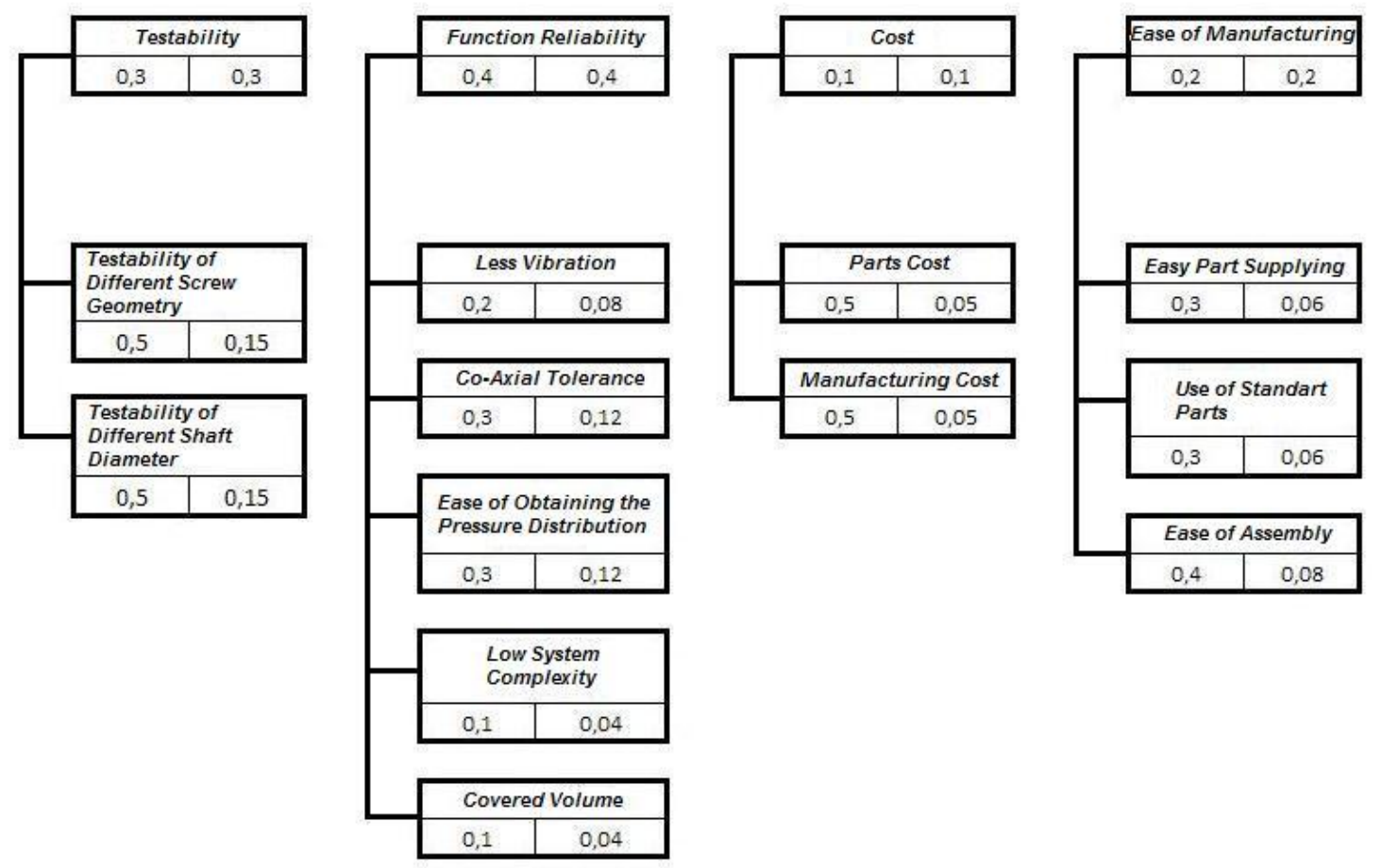

Figure 10. Weighting factors.

\subsection{Evaluation Chart}

The setting up of evaluation criteria and determination of their importance are followed, in the next step, by assigning known parameters to them. These parameters should either be quantifiable, or if that is impossible, are expressed by statements framed as concretely as possible. Figure 11 shows the evaluation chart for the apparatus design, with appropriate magnitudes entered in the relevant variant columns $\left(\mathrm{P}_{\mathrm{i}}\right)$.

The next step is the assessment of values and hence the actual evaluation. These "values" are derived from a consideration of the relative scale of the previously determined parameters. The values are expressed by points. In this study, the evaluation chart employs a range from 0 to 10 . There are some studies used smaller ranges (from 0 to 4 ). The advantage of the wider range is that, classification and evaluation are greatly facilitated by use of a decimal system that reflects percentages. When the sub-values for every variant have been determined, the overall value should be calculated. In the evaluation of the technical products, the summation of the sub-values has become the usual method of calculation.

It has proved very useful to assign such parameters to the evaluation criteria in an evaluation chart before proceeding to the actual evaluation.

According to the evaluation chart on Figure 11, the second solution method is the best alternative for the apparatus system with a weighted rating of $80.3 \%(8.03 / 10)$. 


\begin{tabular}{|c|c|c|c|c|c|c|c|c|}
\hline & & \multirow{3}{*}{\begin{tabular}{|c|}
$\begin{array}{c}\text { Weighting } \\
\text { Factor }\end{array}$ \\
\end{tabular}} & \multirow{2}{*}{\multicolumn{2}{|c|}{ 1st Alternative }} & \multirow{2}{*}{\multicolumn{2}{|c|}{ 2nd Alternative }} & \multirow{2}{*}{\multicolumn{2}{|c|}{ 3rd Alternative }} \\
\hline \multirow{2}{*}{\multicolumn{2}{|c|}{ Evaluation Criteria }} & & & & & & & \\
\hline & & & $P_{i}$ & $\mathrm{~g}^{*} \mathrm{P}_{\mathrm{i}}$ & $\mathbf{P}_{\mathrm{i}}$ & $\mathrm{g}^{*} \mathrm{P}_{\mathrm{i}}$ & $P_{i}$ & $\mathrm{~g}^{*} \mathbf{P}_{\mathrm{i}}$ \\
\hline \multirow{2}{*}{ 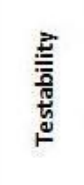 } & $\begin{array}{l}\text { Testability of Different } \\
\text { Screw Geometries }\end{array}$ & 0,15 & 3 & 0,45 & 9 & 1,35 & 6 & 0,9 \\
\hline & $\begin{array}{l}\text { Testability of Different } \\
\text { Shaft Diameters }\end{array}$ & 0,15 & 3 & 0,45 & 9 & 1,35 & 5 & 0,75 \\
\hline \multirow{5}{*}{ 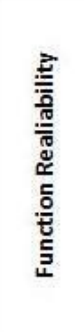 } & Less Vibration & 0,08 & 6 & 0,48 & 7 & 0,56 & 7 & 0,56 \\
\hline & Co-Axial Tolerance & 0,12 & 5 & 0,6 & 8 & 0,96 & 7 & 0,84 \\
\hline & $\begin{array}{l}\text { Ease of Obtaining the } \\
\text { Pressure Distribution }\end{array}$ & 0,12 & 7 & 0,84 & 8 & 0,96 & 4 & 0,48 \\
\hline & $\begin{array}{l}\text { Low System } \\
\text { Complexity }\end{array}$ & 0,04 & 6 & 0,24 & 8 & 0,32 & 7 & 0,28 \\
\hline & Covered Volume & 0,04 & 6 & 0,24 & 7 & 0,28 & 7 & 0,28 \\
\hline \multirow{2}{*}{ है } & Parts Cost & 0,05 & 2 & 0,1 & 7 & 0,35 & 5 & 0,25 \\
\hline & Manufacturing cost & 0,05 & 2 & 0,1 & 6 & 0,3 & 4 & 0,2 \\
\hline \multirow{3}{*}{ 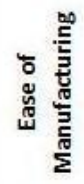 } & Easy Part Suppliying & 0,06 & 8 & 0,48 & 8 & 0,48 & 8 & 0,48 \\
\hline & Use of Standart Parts & 0,06 & 7 & 0,42 & 8 & 0,48 & 8 & 0,48 \\
\hline & Ease of Assembly & 0,08 & 6 & 0,48 & 8 & 0,64 & 7 & 0,56 \\
\hline & $\Sigma=$ & 1 & $\Sigma=$ & 4,88 & $\Sigma=$ & 8,03 & $\Sigma=$ & 6,06 \\
\hline
\end{tabular}

Figure 11. Evaluation chart.

\section{CONCEPTUAL DESIGN}

It appears that, the second solution method ( $2^{\text {nd }}$ alternative) has the highest overall value and the best overall rating. With a weighted rating of $80.3 \%$, second alternative thus represents a good principle solution with which to start the conceptual design phase.

Conceptual design is the part of the design process in which, starting from the principle solution or concept of a technical product, the design is developed in accordance with technical and economic criteria and in the light of further information, to the point where subsequent detail design can lead directly to production.

During the conceptual phase at the least, designers must determine the overall layout design. As shown in Figure 12, the apparatus design was developed by drawing a sketch. 


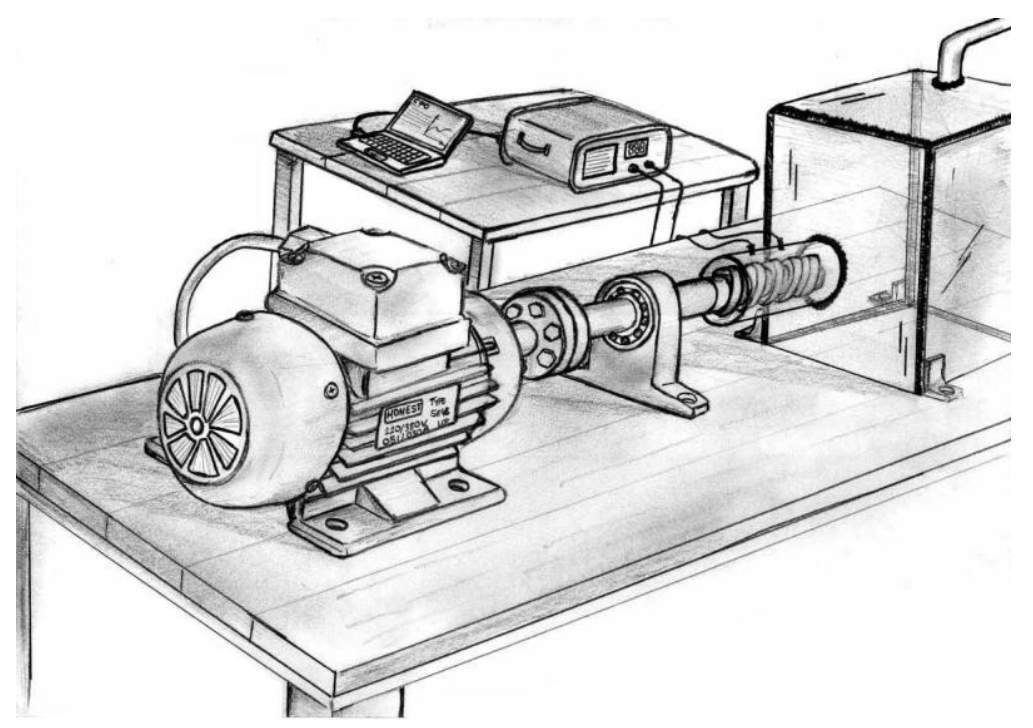

Figure 12. The apparatus design (sketch).

After the preparation of the sketch drawing, the three-dimensional model of the apparatus created with the SolidWorks software (Figure 13).
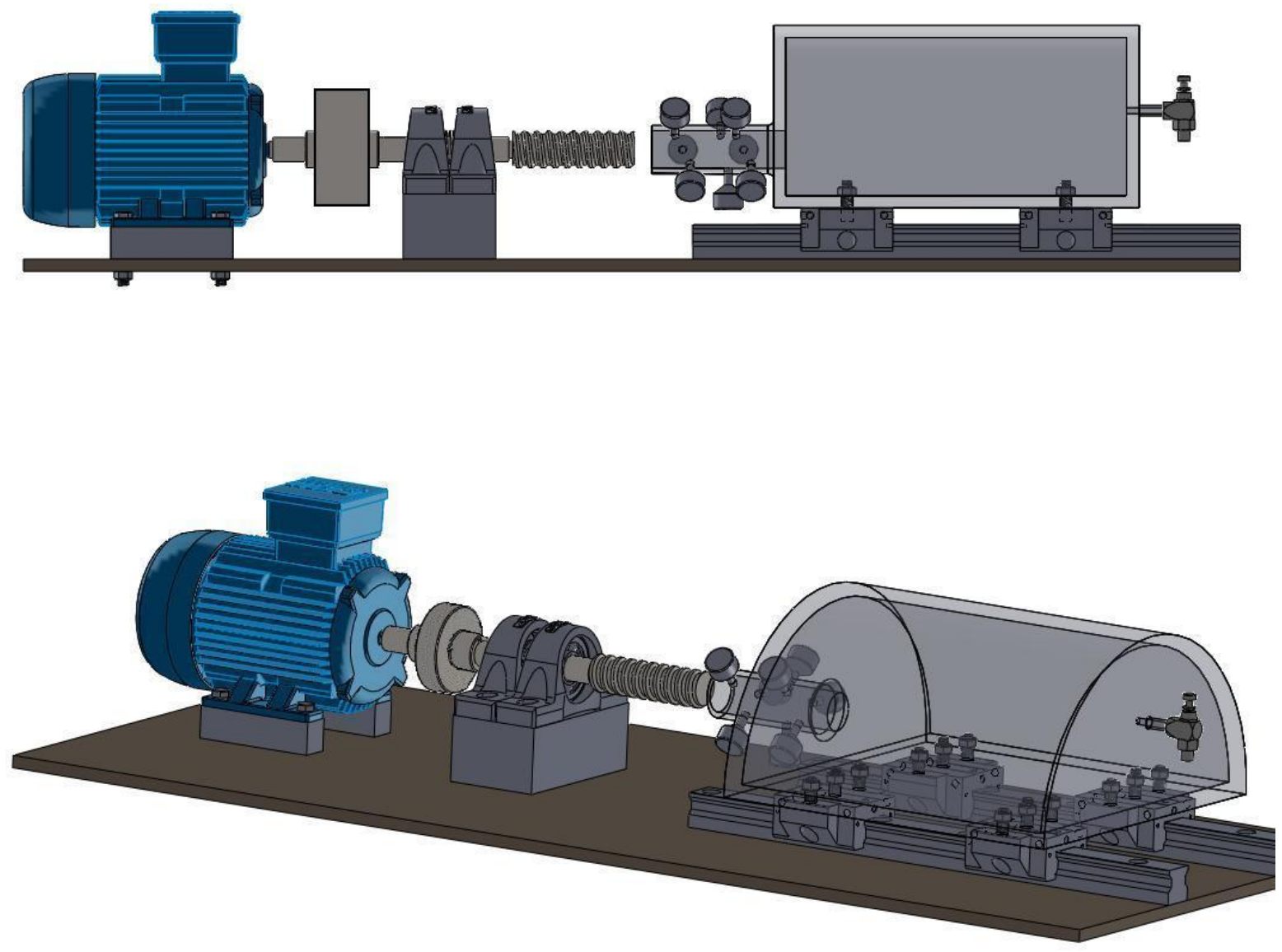

Figure 13. The three-dimensional model of the apparatus. 
It has been suggested that, the design of the apparatus should be covered the expectations of the requirements list, therefore, these expectations are taken into account during the design phase of the apparatus. As mentioned before on the requirements list, the apparatus system needs very small co-axial tolerances. In order to provide these tolerances, preloaded angular contact ball bearings, shown in the figure 15 , were used on the system.
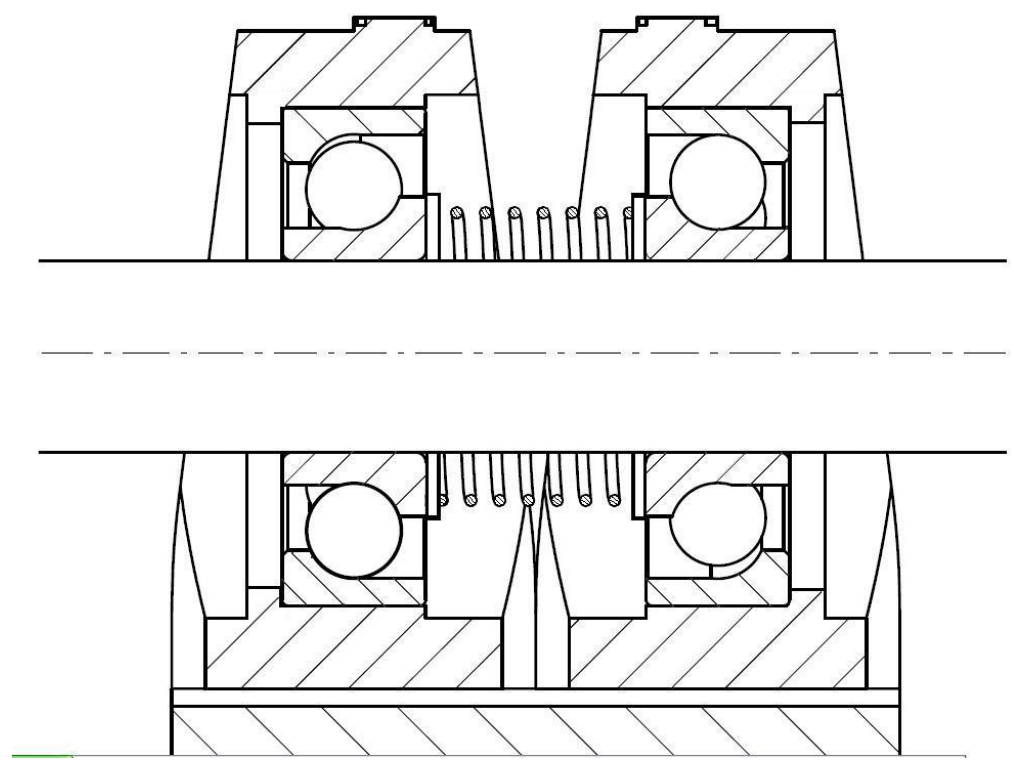

Figure 15. Preloaded angular contact ball bearings.

Different screw geometries should be tested on the apparatus. In order to provide this feature, threaded connection was used on the screwed section of the shaft (Figure 16).
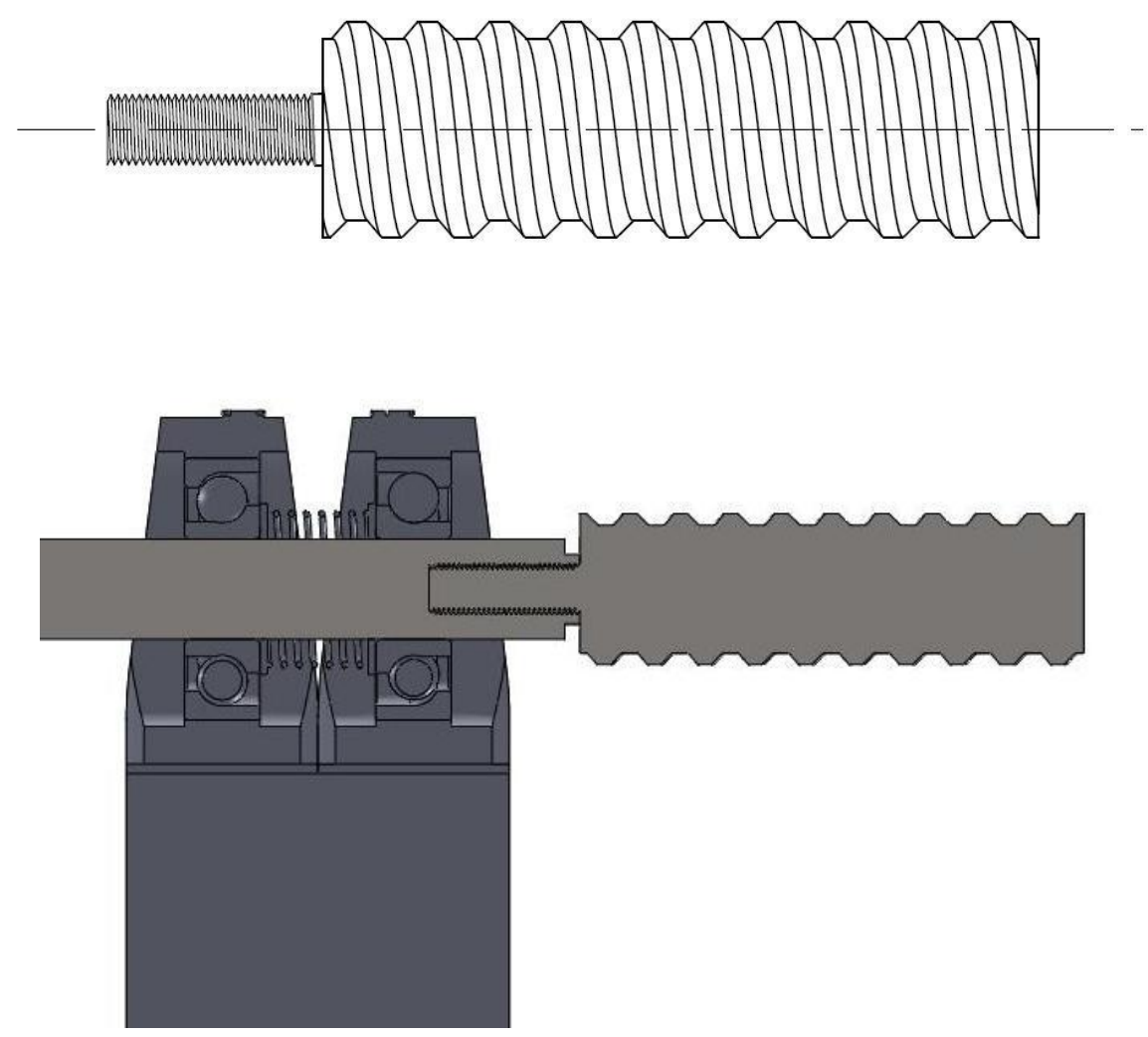

Figure 16. Threaded connection on the shaft. 
The apparatus was designed on a flat surface and motor used on the apparatus allows working at high-speeds. Plexiglas was used on the hub in order to observe the flow on the sealing area. In addition, the pressure distribution on the hub can be obtained by 8 pressure sensors placed at certain intervals, as shown in the Figure 17.

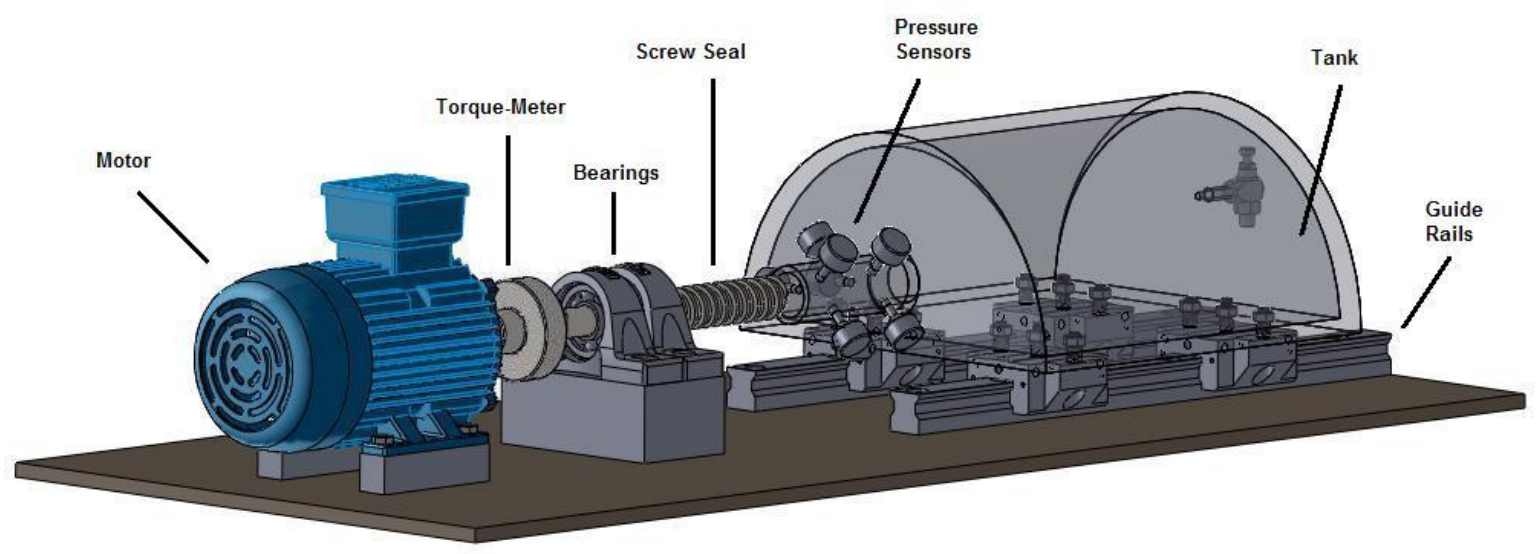

Figure 17. Pressure sensors on the transparent hub.

The axial motion of the pressure vessel is provided with the linear guide rail system (Figure 18).
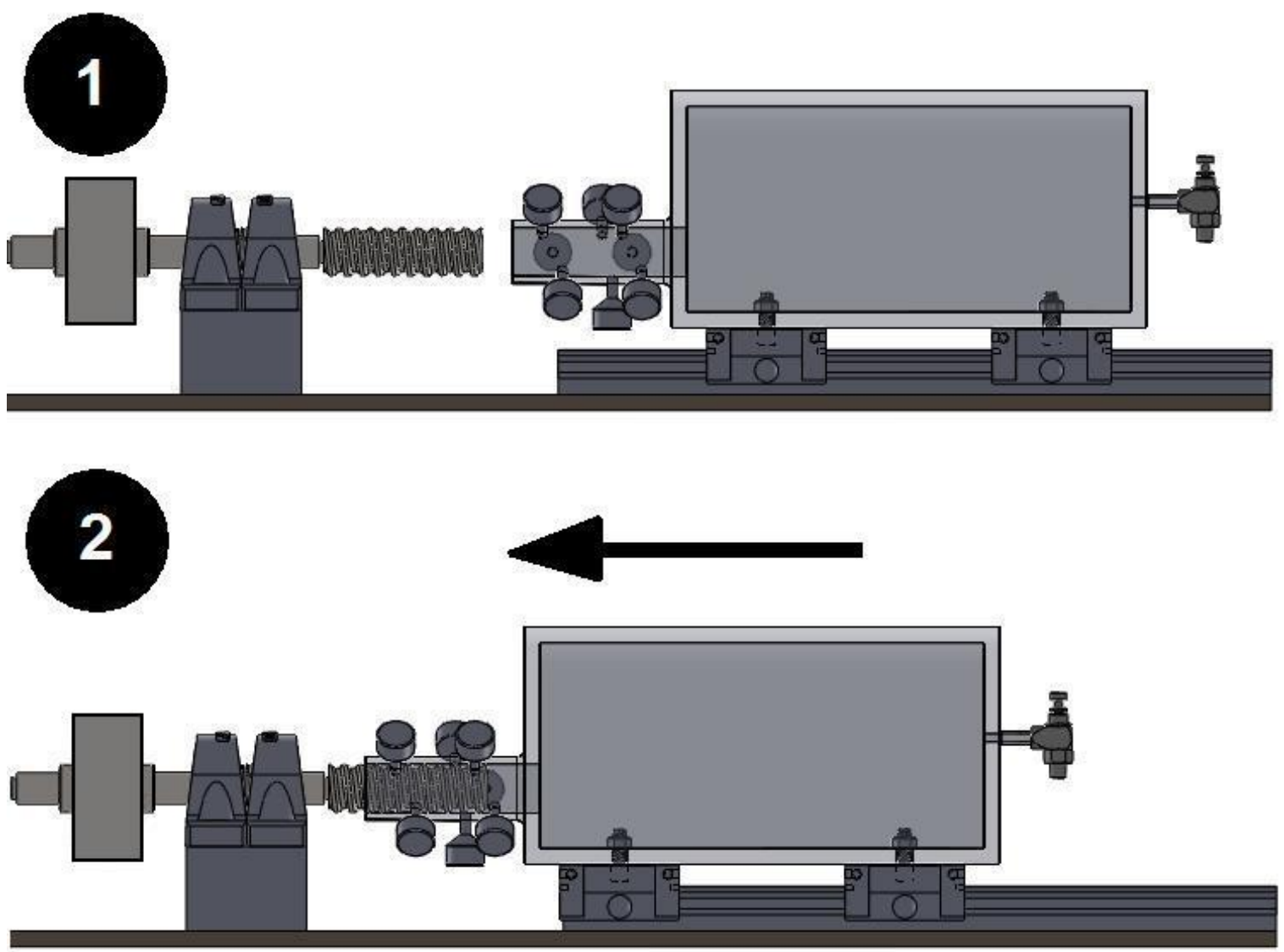

Figure 18. Axial movement of the pressure vessel. 


\section{CONCLUSION}

In this study, the systematic design phases that presented by G. Pahl and W. Beitz were applied to design process of the apparatus that planned to be developed to determine the characteristics of non-contact seals. First, the problem and limitation were defined. After that, the requirements list that shows the expectations from the design, and also qualification and significant status of the materials to be purchased was prepared. Then, the basic function was generated by simplification and abstraction on subject of study; function structures containing the working principle of the apparatus was created and the principle of the solutions that helps to create optimum working system was revealed using the certain methods. Later in the study, the technical-economical evaluation chart showing the optimum working principle of the apparatus was prepared and appropriate working method was selected from the chart. At the end of the study, the conceptual design of the apparatus was developed by considering the systematic approach phases.

\section{REFERENCES}

[1] Alparslan B., Acar B., "Gearbox design for a mini-turboprop engine". $4^{\text {th }}$ Ankara Int. Aerospace Conference., 2007.

[2] Chungling D., Guoying M., "Design of three-stage screw-type labyrinth seal using on main drainage motor in mine and research of its experiment". Electrical Machines and Systems., 2008.

[3] Erkens A., "Beiträge zur konstruktionserziehung”.VDI 72. 17-21, 1928.

[4] Flitney R., "Seals and sealing handbook, fifth edition”., 2007.

[5] Horve L.A., "Shaft seals for dynamic applications"., 1996.

[6] Kesselring F., “Die starke konstruktion”. VDI-Z 86. 321-330, 749-752, 1942.

[7] Kwanka K., "Dynamic coefficients of stepped labyrinth gas seals". Journal of Engineering for Gas Turbines and Power., 2000.

[8] Ludwig P.L., Strom T.N., Allen G.P., "Gas ingestion and sealing capacity of helical groove fluid film seal using sodium and water as sealed fluids". National Aeronautics and Space Administration., 1966.

[9] Leyer A., “Maschinenkonstruktionslehre”. Hefte 1-6 Technica-Reihe., 1963-1971.

[10] Matousek R., “Konstruktionslehre des allgemeinen maschinenbaus”., 1957.

[11] Müller H., Nau B., "Fluid sealing technology. Principles and applications"., 1998. 
[12] Niemann G., "Maschinenelemente"., 1975.

[13] Pahl G., Beitz W., "Konstruktionslehre: Grundlagen erfolgreicher produktentwicklung methoden und anwendung”, 2007.

[14] Redtenbacher F., "Prinzipien der mechanic und des maschinenbaus"., 257-290, 1852.

[15] Tschochner H., “Konstruieren und gestalten”., 1954.

[16] VDI-Frachgruppe Konstruktion, “Engpass konstruktion”., 192-1950, 1967.

[17] Wögerbauer H., "Die technik des konstruierens"., 1943

[18] Yanık O., "Construction of movable shelf in convansional ovens". Master's Thesis, Istanbul Technical University., 2011. 